\title{
Distal amyotrophy of predominantly the upper limbs with pyramidal features in a large kinship
}

\author{
EM VAN GENT, ${ }^{*}$ RA HOOGLAND, † FGI JENNEKENS* \\ From the Departments of Neurology* and Clinical Neurophysiology, $\dagger$ University Hospital, Utrecht, The \\ Netherlands
}

SUMMARY An autosomal dominant disease characterised by amyotrophy of predominantly distal upper limb muscles and mild pyramidal features is described. There are sensory changes in older $\vec{\circ}$ patients, whilst in others the disease presents itself as a disorder of motor neurons. Owing to $\overrightarrow{\vec{H}}$ variations in the clinical picture, it may be difficult to distinguish this disease in individual patients $\vec{\omega}$ from distal spinal muscular atrophy, or from pure pyramidal syndromes. There is an overlap in clinical signs between this disease and peroneal muscular atrophy with pyramidal features. Whether or not the latter two conditions are genetically distinct, is a matter of doubt.

In 1966, Silver ${ }^{1}$ described two families in this Journal with an autosomal dominant disease characterised by amyotrophy of predominantly distal muscles of the upper limbs and pyramidal disturbances of predominantly the lower limbs. The onset of this disease was in the second decade and progress was very slight with no shortening of life. Classification of Silver's disease became a matter of divergent opinion. It was regarded by some as a variant of hereditary motor and sensory neuropathy type $\mathrm{V}^{2}$, whilst others felt that it was a special form of spastic paraplegia with amyotrophy. ${ }^{34}$ We recently had the opportunity to examine 18 affected members of another large kinship with this disease. We undertook the investigation in order to delineate as accurately as possible the variability of the clinical picture.

\section{Index patient}

(Case V4, Figure and Table)

This patient experienced slight difficulty in walking from the age of 11 years. When he was 36 years old, neurological examination disclosed bilateral pes cavus, right thenar atrophy, bilateral peroneal muscle atrophy and weakness

Address for reprint requests: Dr FGI Jennekens, Laboratory for Neuromuscular Diseases, University Hospital, Postbus 16250, 3500 CG Utrecht, The Netherlands.

Received 1 May 1984 and in revised form 11 July 1984. Accepted 21 July 1984 of atrophic muscles. Tendon reflexes of the limbs we raised. We saw the patient for the first time when he was 6 을 years of age. His complaints then concerned decrease $\mathrm{f}$ hand power and increased difficulty in walking. He had 3 paraesthesiae and experienced only occasional cramping of the calf muscles. There was a marked degree of intrinsio hand muscle atrophy together with atrophy of the $\vec{v}$ peroneal muscles. Tendon reflexes of the limbs were raiseg $œ$ with the exception of the ankle reflexes which were absent. of The tone of the lower limb muscles was raised and $\square$ Babinski reflexes were present. The vibration sense was disturbed below the knees and there was hypaesthesia and hypalgesia from half way down the lower legs. Electromyography revealed denervation potentials and loss of $\frac{\mathrm{O}}{\overline{\mathrm{O}}}$ motor units in distal limb muscles. Stimulation of the $\unrhd$ median nerve at the wrist did not elicit any potential. $\vec{F}$ Motor and sensory conduction velocities and distal laten- $\frac{0}{3}$ cies of the ulnar nerve were normal. The sensory action potential at the the elbow was regarded as abnormal, because of severe polyphasia. Myelinated nerve fibre density in a biopsy of the left sural nerve was decreased ( 740 per $0.2 \mathrm{~mm}^{2}$, or 3900 per $\mathrm{mm}^{2}$; in normal adults $>7000^{5}$ ). Nerve fibre diameters varied from 1-14 $\mu \mathrm{m}$. A $\bar{\sigma}$ histogram of 1000 myelinated nerve fibres showed a nor- 3 . mal first peak at $3 \mu \mathrm{m}$, whilst the second peak at $8 \mu \mathrm{m}$ was $\delta$ not present, due to loss of large myelinated nerve fibres. Examination of 29 teased nerve fibres showed paranodal demyelination once and occasional remyelinated segments.

\section{Description of the family}

Six generations are represented in the pedigree (fig). The disease was present in some members of each generation. 


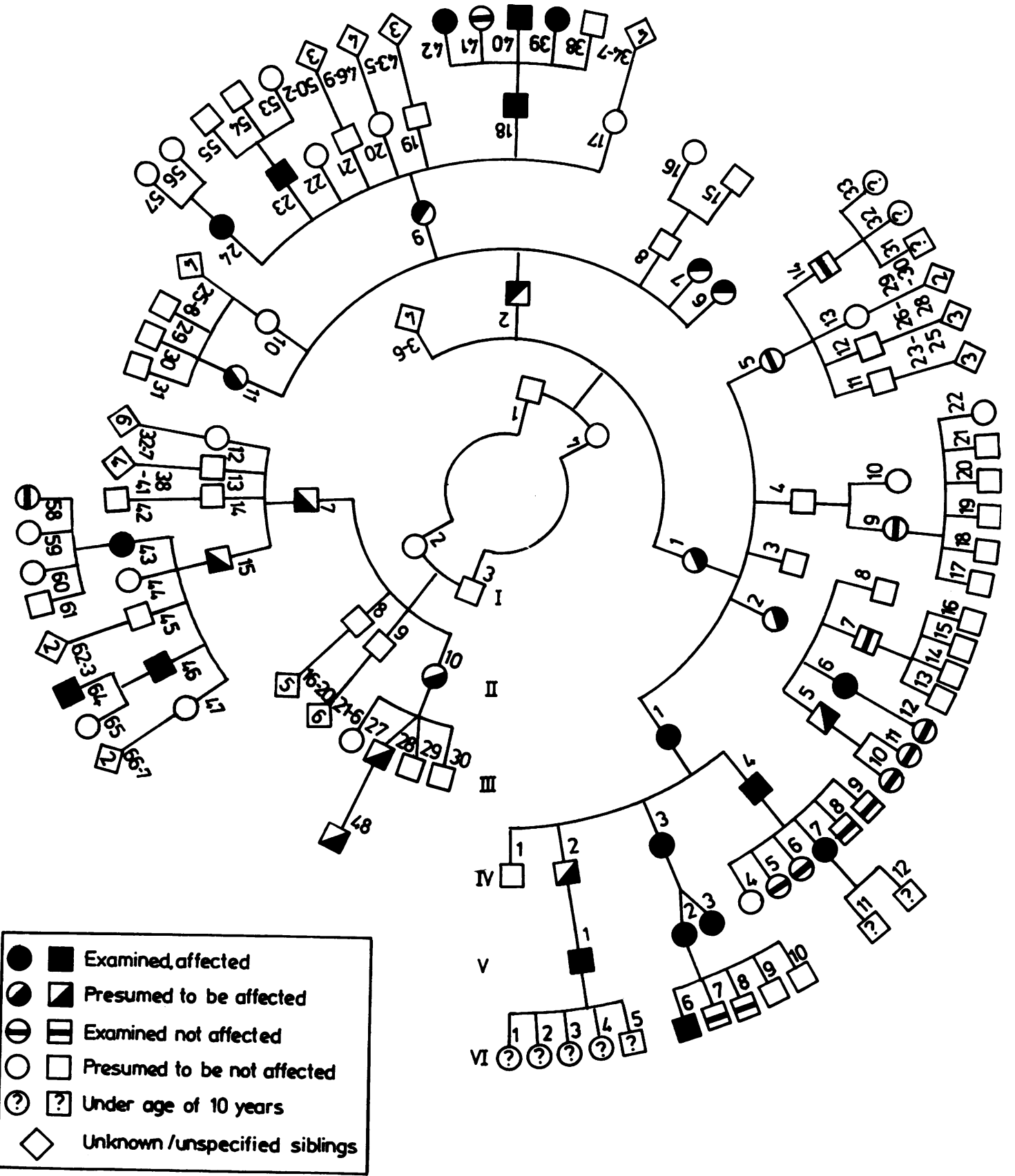

Fig Pedigree of six generations. 
neurological abnormalities.

\section{Discussion}

Amyotrophy is known to develop in several chronic hereditary diseases of the pyramidal tract and these conditions have recently been reviewed. ${ }^{4-6}$ In one of these conditions, muscular weakness and atrophy develop early are located predominantly in distal muscles of the lower limbs. ${ }^{\circ}$ Distal upper limb muscles in this condition are often also involved, and in occasional members of such families, hand muscle atrophy is even more severe than peroneal muscle atrophy. The disorder in the present kinship closely resembled the disease described by Silver.' Inheritance was autosomal dominant without preference for either sex. Atrophy of the hand muscles was often marked (11 out of 18 cases) and more severe and more frequent than atrophy of lower limb muscles. Thenar atrophy was in some patients unilateral and only present on the right side. Clinical evidence of sensory disturbances were only seen in aged patients. In some aspects, the syndrome in the present family differed slightly from that in Silver's families. Complaints of hand muscle weakness were less often the presenting symptoms and pyramidal disturbances were less severe and were never the only clinical findings. Histological and electrophysiological investigations showed nerve fibre degeneration to be neuronal or axonal in origin. These investigations were not performed by Silver.

Distal muscular atrophy of the upper limbs with pyramidal features presents in most patients as a disorder of motor neurons and classification as a mixed motor and sensory neuropathy is not, therefore, the most logical conclusion. Minor involvement of sensory neurons is well known in both hereditary ${ }^{7}$ and non-hereditary ${ }^{8}$ forms of motor neuron disease. In individual patients, the disease may be expressed as distal spinal muscular atrophy or as a pure pyramidal syndrome. The differentiation between hereditary distal lower and distal upper limb muscular atrophy with pyramidal features, is not always possible in individual patients and whether these two syndromes have to be distinguished as separate genetic entities is doubtful.

The discovery of thyroid antibodies in almost equal percentages of affected (16\%) and non- affected (20\%) members of this kinship, came as a surprise. The incidence of these antibodies in the Dutch population is between $0 \%$ and $3 \% .^{910}$ The combination within one family of hereditary antibodies against thyroid tissue and the described neurological syndrome may be a coincidence.

We thank Mrs. S. Dierks-Mallett for secretarial assistance and Mr. H. Veldman for technical assistance.

\section{References}

' Silver JR. Familial spastic paraplegia with amyotrophy of the hands. J Neurol Neurosurg psychiatry 1966;29: 135-44.

${ }^{2}$ Dyck PJ. Inherited neuronal degeneration and atrophy affecting peripheral motor, sensory and autonomic neurons. In: Dyck PJ, Thomas PK and Lambert EH eds. Peripheral Neuropathy. Philadelphia: WB Saunders, 1975:825-67.

${ }^{3}$ Rowland LP. Diverse forms of motor neuron disease. In: Rowland LP ed. Human Motor Neuron Diseases. Advances in Neurology, vol. 36. New York: Raven Press, 1982:1-13.

4 Harding AE. Classification of the hereditary ataxias and paraplegias. Lancet 1983;1:1151-4.

s Dyck PJ, Lambert EH, Nichols PC. Quantitative measurement of sensation related to compound action potential and number and sizes of myelinated and unmyelinated fibres of sural nerve in health. Freidreich ataxia, hereditary sensory neuropathy and tabes dorsalis. In: Rémond A ed. Handbook of Electroencephalogaphy and Clinical neurophysiology, Vol. 9, Amsterdam, Elsevier 1971:83-118.

- Harding AE, Thomas PK. Peroneal muscular atrophy with pyramidal features. J Neurol Neurosurg Psychiatry 1984;47:168-72.

${ }^{7}$ Horton WA, Roswell E, Brody JA. Familial motor neuron disease. Evidence for at least three different types. Neurology (Minneap) 1976;26:460-5.

${ }^{8}$ Bradley WG, Good P, Rasool CG, Adelman LS. Morphometric and biochemical studies of peripheral nerves in amyotrophic lateral sclerosis. Ann Neurol 1983;14:267-77.

${ }^{9}$ Feltkamp TEW. Idiopathic auto-immune diseases. A study of their neurological relationship. M.D. Thesis, Amsterdam, 1966.

${ }^{10}$ Feltkamp TEW. Klinische Immunologie. Utrecht: Bohn, Scheltema and Holkema, 1980:90-113. 